\title{
PROCESSOS BIM DE COORDENAÇÃO 3D E REVISÃO DO CLIENTE. O EXEMPLO DO EDIFÍCIO RESIDENCIAL DE BEN AKNOUN
}

\author{
Miguel Saraiva $^{(1)}$, Guilherme Gomes ${ }^{(1)}$, Daniel Moutinho ${ }^{(1)}$ \\ (1) TPF CONSULTORES DE ENGENHARIA E ARQUITETURA, S.A., Lisboa
}

\section{Resumo}

No âmbito da execução de um projeto de um novo edifício de apartamentos em Ben Aknoun, Argélia, desenvolveram-se as soluções das várias disciplinas que compõem o projeto, com recurso a metodologias BIM.

Realizou-se um trabalho colaborativo entre as várias disciplinas, nomeadamente arquitetura (ARQ), estruturas (EST), abastecimento de água (ABA), drenagem (DRE), gás (GAS) e climatização (AVAC), cumprindo o estipulado preliminarmente no Plano de Execução BIM. Os modelos BIM, todos realizados no programa Revit, foram carregados para um modelo federado do Navisworks, com o objetivo de se realizar a coordenação das disciplinas e detetar colisões entre modelos. A comunicação dessas colisões foi posteriormente feita aos responsáveis de cada disciplina, através da aplicação BIMcollab, com o fim de facilitar a comunicação com os projetistas.

O trabalho colaborativo, para ser eficiente, exige que seja despendido tempo inicial na organização dos procedimentos e que sejam estabelecidas regras de comunicação. Todo este processo e a aplicação conjunta de ferramentas BIM na coordenação do projeto, vieram a revelar-se muito úteis, permitindo diminuir, significativamente, as interferências dos projetos das diferentes disciplinas.

\section{Introdução}

O desenvolvimento do projeto de arquitetura e de todas as disciplinas de um edifício habitacional, situado no bairro de Ben Aknoun, em Argel, na Argélia, abriu a possibilidade de aplicar usos BIM que até à data ainda não tinham sido explorados no desenvolvimento dos projetos da TPF Consultores, nomeadamente ao nível da interação com o cliente e da coordenação do projeto.

O edifício, com uma área bruta de construção de $8165 \mathrm{~m}^{2}$ e uma área de implantação de $784 \mathrm{~m}^{2}$, tem 13 pisos acima do solo, 3 caves e um piso térreo, é constituído por 28 apartamentos de gama alta, 1 creche, 1 ginásio e estacionamento para 32 automóveis. 
Dada a maturidade da empresa na utilização de usos BIM como extração de peças desenhadas e de quantidades, optou-se por implementar neste projeto outros usos BIM, como a revisão do projeto de arquitetura pelo cliente e a coordenação 3D das disciplinas. Os principais objetivos passaram por obter um produto final que fosse o mais adaptado às necessidades do cliente e um projeto compatibilizado ao máximo entre as várias disciplinas.

Para cumprir com esses objetivos, foi necessário desenvolver um PEB detalhado, com os mapas de processos dos novos usos BIM, tornando claro o processo colaborativo e definindo os limites de responsabilidade de cada interveniente.

Todos os projetos de especialidades foram desenvolvidos com recurso ao Revit. A coordenação dos modelos e a análise de colisões foram desenvolvidas com recurso ao Navisworks, utilizando o BIMcollab como ferramenta de comunicação digital das interferências.

Com o presente artigo pretende-se transmitir o processo de aplicação destes usos BIM e as dificuldades sentidas em cada um deles.

\section{Elaboração do Plano de Execução BIM (PEB)}

Com o objetivo de definir e compatibilizar o contributo das equipas envolvidas no desenvolvimento dos modelos, durante as fases do projeto, procedeu-se à execução de um PEB. Este documento foi criado na fase que antecede o início dos projetos e foi aprovado por todos os projetistas envolvidos. O PEB esteve acessível durante todo o processo, de modo a poder ser consultado a qualquer altura pelos vários intervenientes e adaptado ao desenvolvimento do projeto.

O PEB contém uma caracterização geral do projeto e define as prioridades dos vários objetivos BIM. Define também os intervenientes, os respetivos contactos, as fases e nível de desenvolvimento dos modelos por fase, assim como os softwares a utilizar, trocas de informação, mapas de processos, a estrutura da plataforma colaborativa e os usos BIM.

Os principais objetivos do projeto, assim que se definiu que o seu desenvolvimento seria com recurso à metodologia BIM, foram o de reduzir o tempo empregue com revisões de projeto, recorrendo a ferramentas que facilitam a deteção de colisões, e permitir o acompanhamento do desenvolvimento do projeto por parte do cliente, proporcionando uma melhor perceção do trabalho realizado.

Para se atingir os objetivos estipulados, foram inseridos dois usos BIM, que, até à data, ainda não tinham sido explorados internamente, nomeadamente a revisão do projeto de arquitetura pelo cliente a partir do modelo BIM e a coordenação 3D. Outros usos BIM têm vindo a ser consolidados ao longo da execução de outros projetos realizados pela empresa, nomeadamente a modelação das condições existentes, desenvolvimento do projeto e a extração de peças desenhadas e de quantidades.

Para os novos usos BIM estabeleceram-se mapas de processos que visam detalhar o fluxo dos mesmos. A Figura 1 refere-se ao mapa de processos da revisão do projeto pelo cliente. Este mapa, com um fluxo simplificado, consiste em apresentar o modelo BIM ao cliente e obter uma aprovação deste, antes de se detalhar o projeto. 


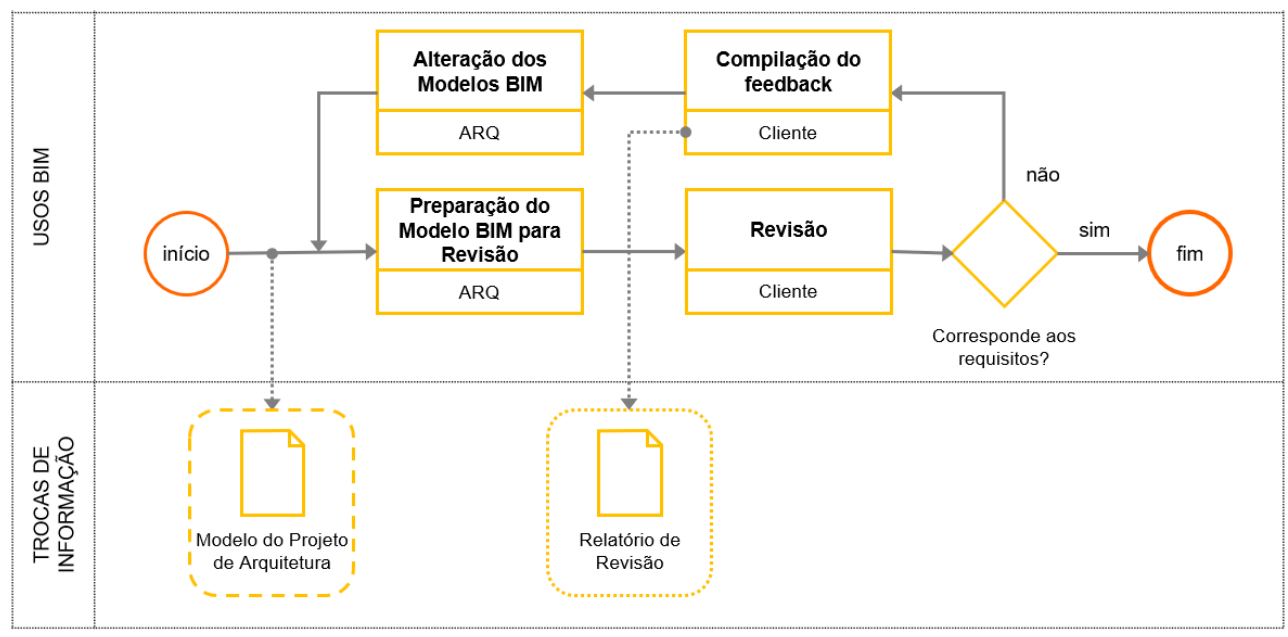

Figura 1: Mapa de processos. Revisão do projeto de arquitetura pelo cliente.

Sabendo à partida que o cliente não tinha conhecimentos BIM e apesar de poder utilizar ferramentas de visualização gratuitas e intuitivas, optou-se por um processo de revisão que compreendia uma análise visual do modelo com recurso a realidade virtual (RV), acompanhado pela equipa do projeto, num formato de reunião presencial. O resultado foi um relatório com comentários e alterações relativos ao projeto de arquitetura. Este uso BIM poderá ser potenciado noutros casos, em que o cliente domine ferramentas BIM, por forma a comunicar as revisões em plataformas colaborativas, após uma análise pormenorizada aos modelos.

O processo de coordenação iniciou-se com a produção do PEB e a transmissão dos requisitos às equipas do projeto. Após definida a plataforma colaborativa, o cronograma de coordenação e os seus critérios, iniciou-se a análise dos modelos, com vários ciclos de revisão.

Na Figura 2 apresenta-se o mapa de processos do uso BIM coordenação 3D.

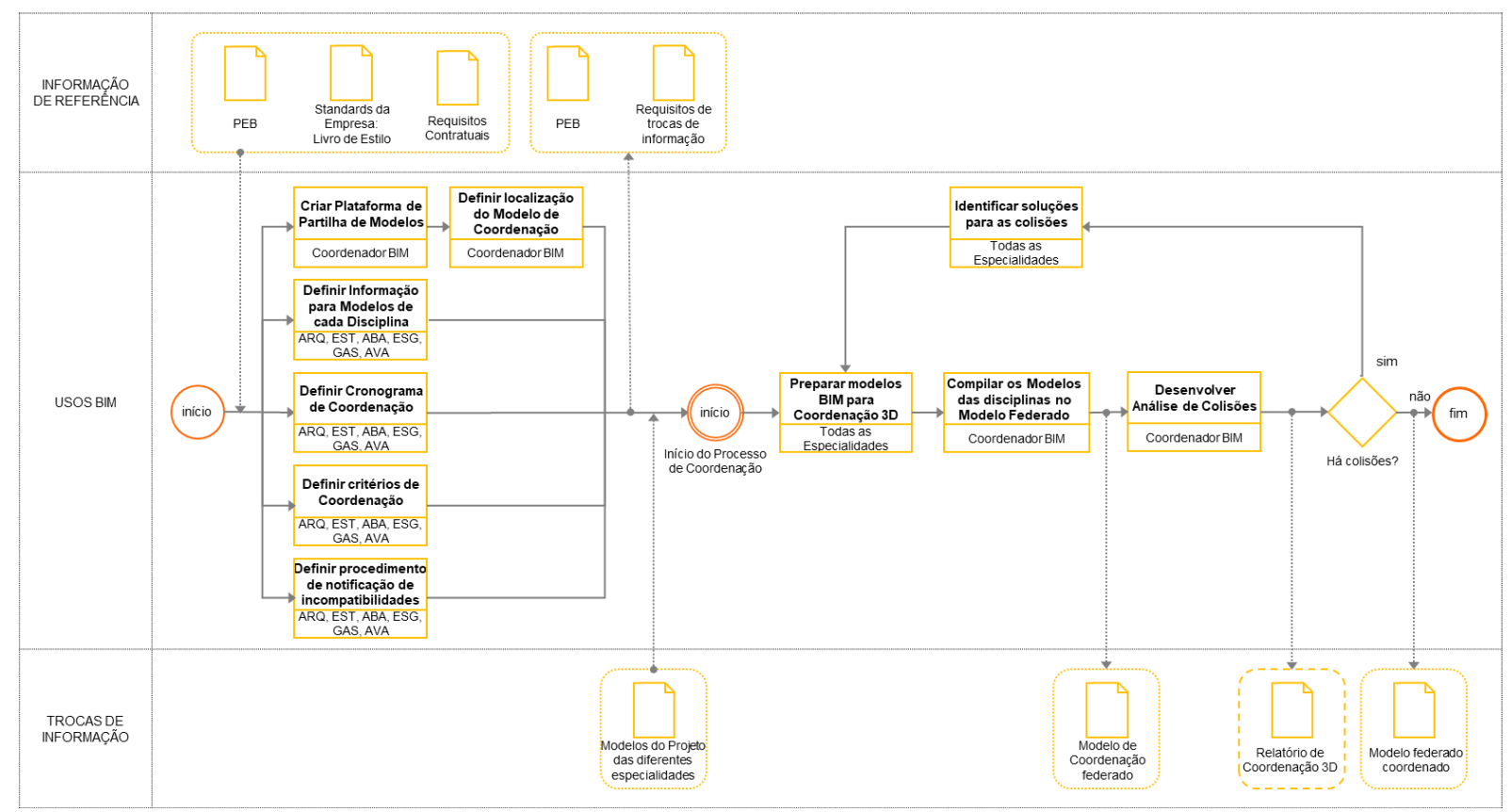

Figura 2: Mapa de processos. Coordenação 3D. 
Durante a elaboração do projeto houve a necessidade de reformular o processo de coordenação previsto no mapa de processos do PEB e detalhar o processo do ciclo de revisão, de acordo com o fluxo que se apresenta na Figura 3.

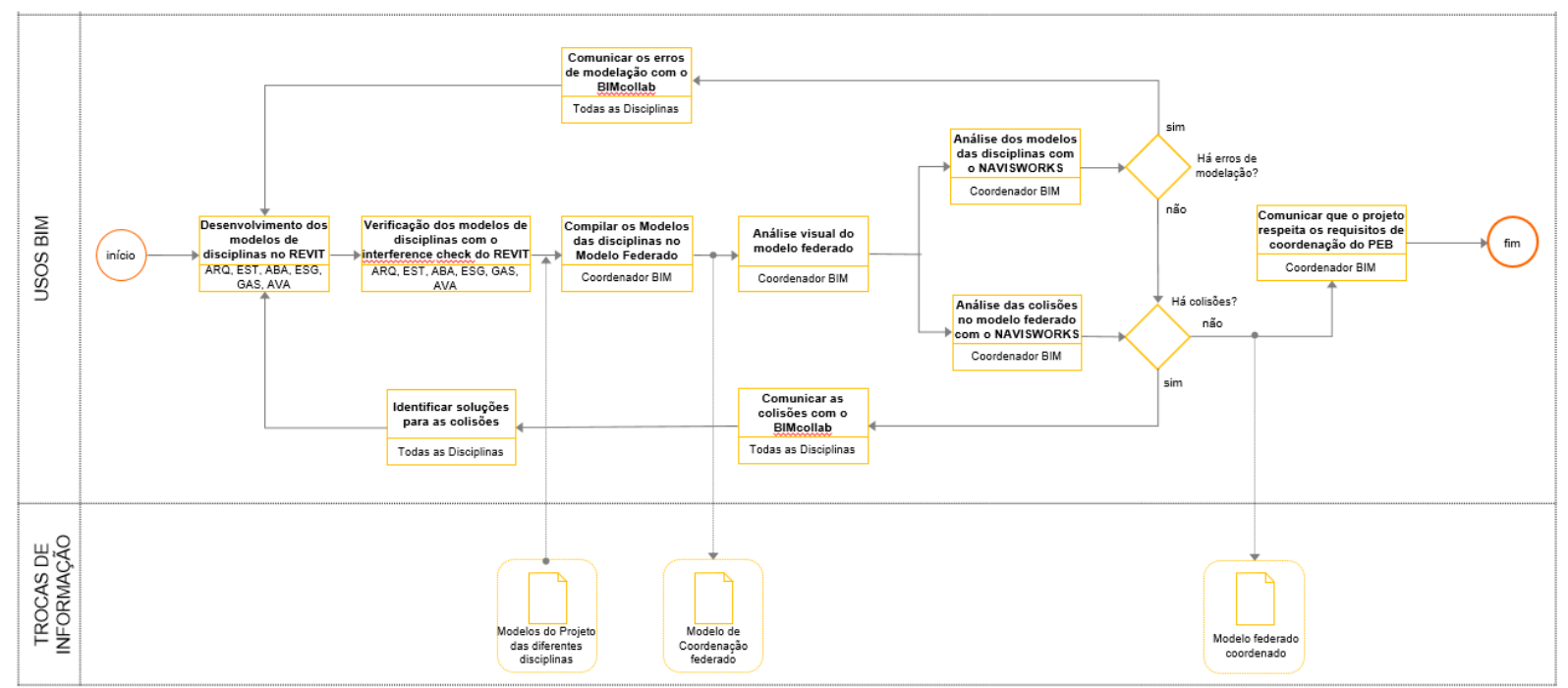

Figura 3: Ciclo de revisão dos modelos. Fluxo.

Este fluxo foi desenvolvido à medida que se foram testando as ferramentas usadas na coordenação 3D, tendo-se incluído o BIMcollab para ferramenta de comunicação de colisões.

\section{O ambiente BIM na comunicação com o cliente}

O projeto de arquitetura começou a ser desenvolvido, desde o início, com recurso a um modelo em Revit. A utilização de uma ferramenta BIM, numa fase prematura do projeto, não só permitiu ao arquiteto estudar o conceito e respeitar o caderno de encargos, como também facilitou a comunicação com o cliente durante a criação conceptual.

Inicialmente realizou-se uma apresentação do projeto de arquitetura com recurso à apresentação de várias imagens e axonometrias extraídas do modelo, transmitindo-se de uma forma mais imediata o conceito arquitetónico e facilitando a comunicação dos esquemas volumétricos.

Aprovado o Estudo Prévio, realizou-se uma apresentação do projeto ao cliente com recurso a $\mathrm{RV}$. A apresentação com recurso a RV necessitou apenas da ferramenta de comunicação 3D (Kubity), de um smartphone, de uns óculos de RV e de um joystick. A aplicação escolhida comunica através de uma nuvem, para onde é carregado o modelo 3D e que é acessível por intermédio de computadores, tablets ou smartphones. Os óculos e o joystick, conectados por bluetooth ao smartphone, permitiram navegar pelo modelo, ter uma perceção mais realista da relação entre espaços e entender a escala do edifício com a envolvente.

Do ponto de vista da solução arquitetónica, a utilização desta ferramenta permitiu justificar de uma forma muito mais clara a solução adotada para os painéis de fachada do edifício, visto que o cliente pretendia uma solução suficientemente translúcida para entrar luz nos apartamentos e simultaneamente opaca para conferir privacidade. 
Na Figura 4 apresenta-se uma fotografia tirada durante a preparação da a apresentação do projeto ao cliente, onde se pode visualizar o interveniente da direita a utilizar os óculos de RV e o joystick.

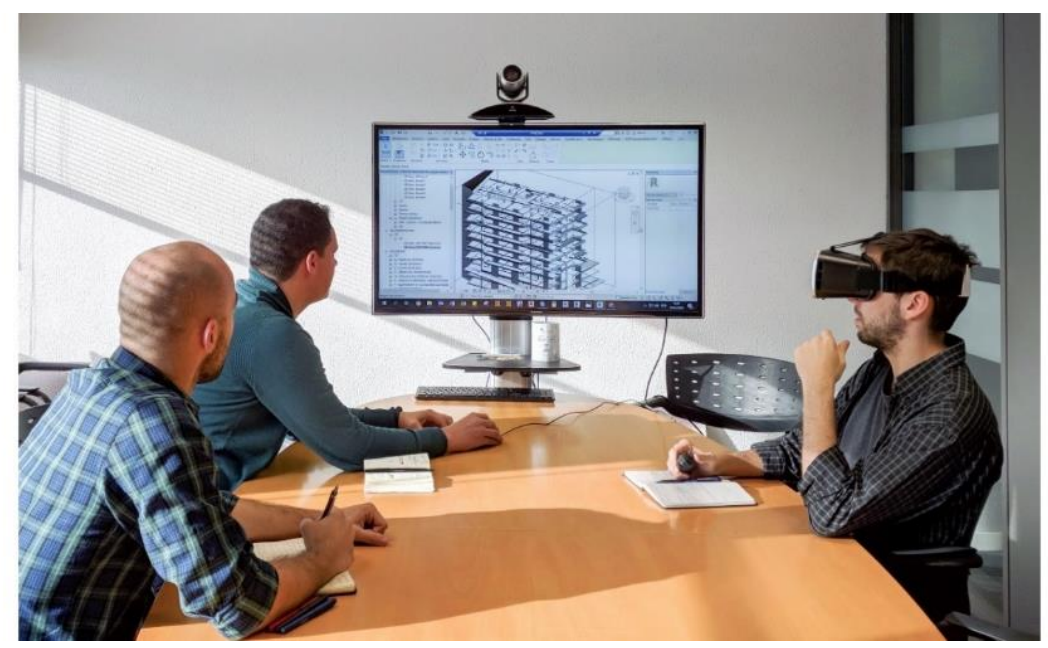

Figura 4: Preparação da apresentação do modelo ao cliente.

O resultado desta apresentação foi muito positivo, porque permitiu transmitir ao cliente, com clareza, todos os esquemas de princípios arquitetónicos e justificar em que medida estavam cumpridos todos os requisitos do caderno de encargos. Foi também importante para reduzir o risco de retificações ou alterações, nas fases seguintes, por falta de comunicação arquiteto/cliente. A implementação deste uso BIM não é complexa, necessitando apenas de um investimento em hardware.

Em projetos futuros, este processo de comunicação do projeto através de RV poderá ser complementado com a utilização do A360 (visualizador gratuito), que possibilita a exploração do modelo de forma independente pelo cliente.

\section{Coordenação do projeto com recurso a ferramentas BIM}

\subsection{Modelo federado e análise de colisões}

A utilização deste uso BIM envolveu apenas a fase do projeto de execução. Antes de se fazer a partilha dos modelos, cada responsável executou a verificação interna do seu modelo, através do interference check do Revit. Esta etapa permitiu evitar alguns erros de ligação dos elementos dos modelos, para que não fossem posteriormente listados como interferências da coordenação. Após a partilha no servidor interno da empresa, usado neste caso como plataforma colaborativa, o BIM Manager carregou os modelos de ARQ, EST, ABA, ESG, GAS e AVAC para um modelo federado no Navisworks.

Nas Figuras 5 e 6 apresentam-se vistas do modelo federado completo, com os modelos de todas as disciplinas sobrepostos. Na Figura 7 apresenta-se uma vista tridimensional de um piso com os modelos das disciplinas sobrepostos, com exceção do modelo de ARQ. 


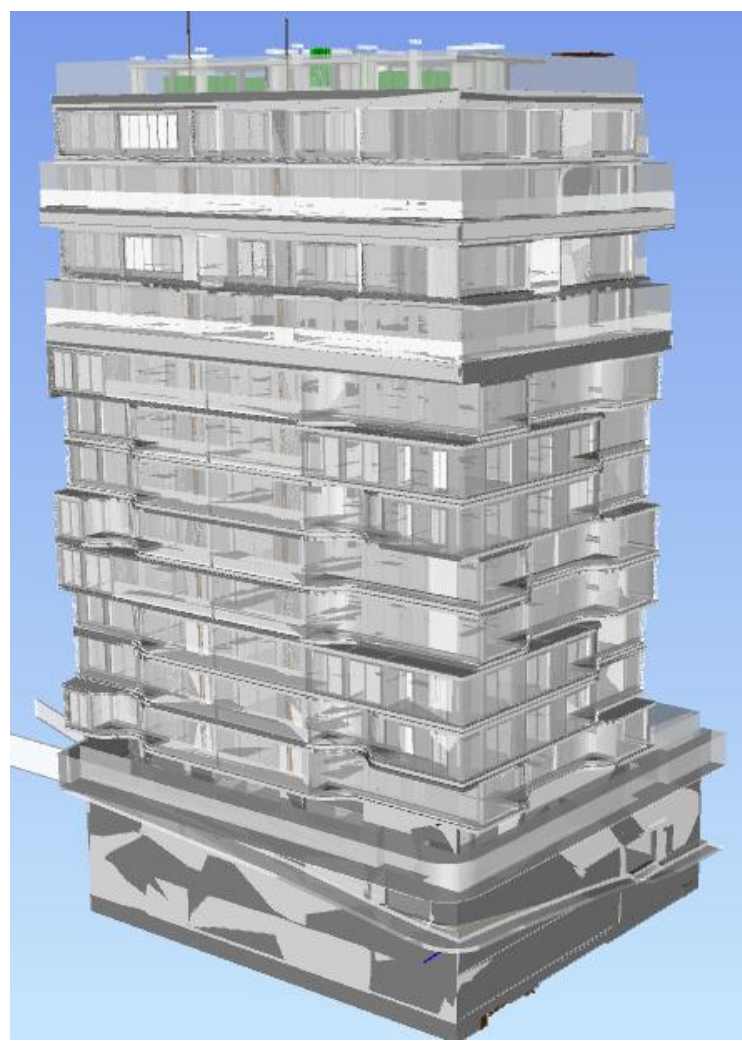

Figura 5: Vista geral do modelo Federado.

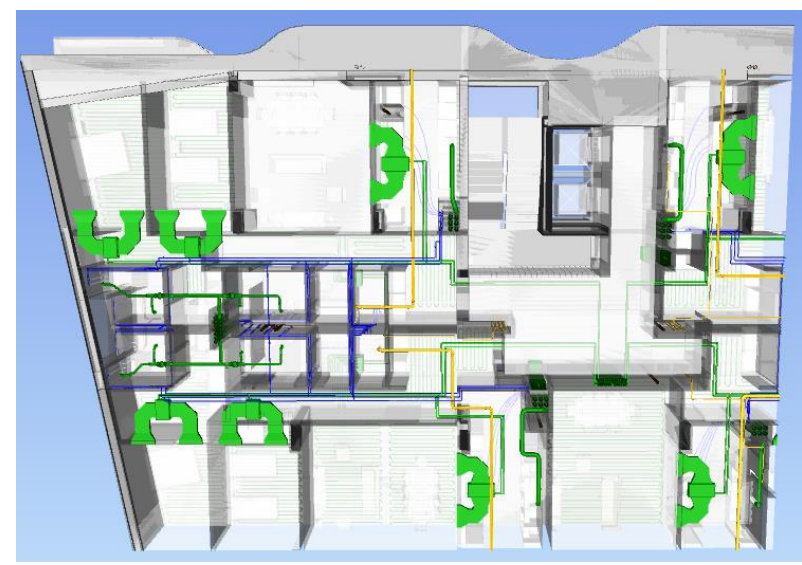

Figura 6: Planta de um piso.

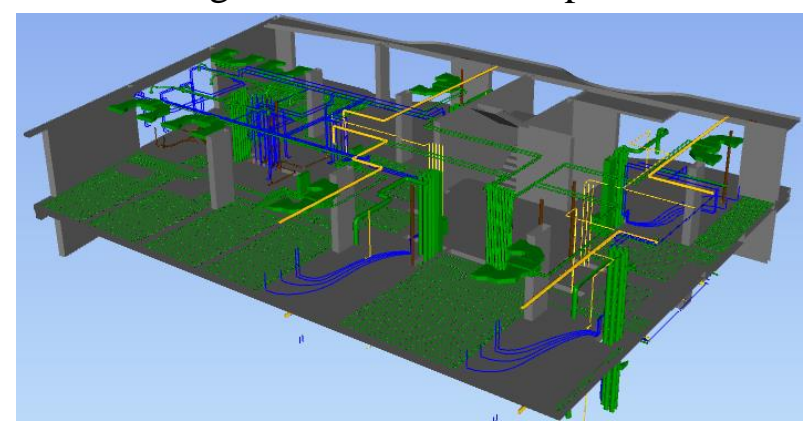

Figura 7: Vista 3D de um piso. $\because \mathrm{EST} \square \mathrm{ABA} \square \mathrm{ESG} \quad \mathrm{GAS} \backsim \mathrm{AVAC}$

Após criado o modelo federado, a função do BIM Manager, em cada ciclo de revisão, foi dividida em três etapas. Numa primeira, fez-se uma análise visual ao modelo federado com o objetivo de detetar incongruências evidentes, nomeadamente problemas de georreferenciação dos modelos ou interferências de projeto. Na etapa seguinte, realizou-se uma análise individual a cada modelo, de modo a detetar problemas de modelação. Posteriormente verificaram-se as colisões entre as diferentes disciplinas. Para facilitar a análise das colisões e conseguir filtrar a informação relevante, agruparam-se as verificações entre disciplinas de acordo com o apresentado na Tabela 1.

Tabela 1: Grupos de disciplinas para a análise de colisões

\begin{tabular}{ccccccc}
\hline & ARQ & EST & ABA & ESG & GAS & AVA \\
\hline Grupo 1 & $\mathrm{x}$ & $\mathrm{x}$ & & & & \\
Grupo 2 & $\mathrm{x}$ & & $\mathrm{x}$ & $\mathrm{x}$ & $\mathrm{x}$ & \\
Grupo 3 & $\mathrm{x}$ & & & & & $\mathrm{x}$ \\
Grupo 4 & & $\mathrm{x}$ & $\mathrm{x}$ & $\mathrm{x}$ & $\mathrm{x}$ & \\
Grupo 5 & & $\mathrm{x}$ & & & & $\mathrm{x}$ \\
Grupo 6 & & & $\mathrm{x}$ & $\mathrm{x}$ & $\mathrm{x}$ & $\mathrm{x}$ \\
\hline
\end{tabular}


Uma das dificuldades sentidas no processo de análise de colisões foi o tratamento da informação obtida. Numa primeira fase, a análise resultou em milhares de colisões entre os modelos. Muitas dessas colisões não existem na prática ou são de resolução fácil, como é o caso das colisões dos espaços arquitetónicos (rooms) com elementos do modelo (Figura 8a), das colisões entre o mobiliário não fixo e outros elementos (Figura 8c), a duplicação de elementos estruturais nas disciplinas de arquitetura e estrutura (Figura 8b), interseções entre tubagens e paredes divisórias (Figura 8d), etc.

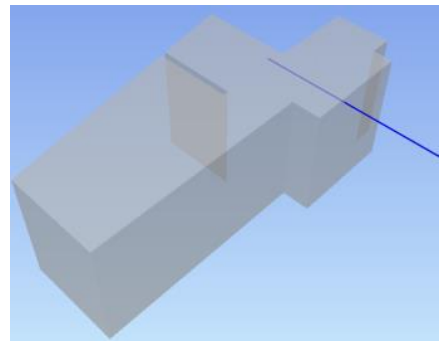

a)

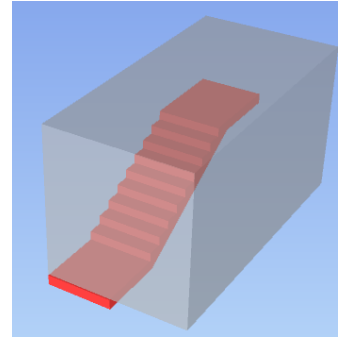

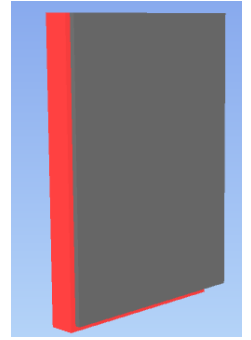

b)

Figura 8: a) Colisões entre espaços (rooms) e outros elementos; b) Colisão por duplicação de elementos estruturais nos modelos de ARQ e de EST.
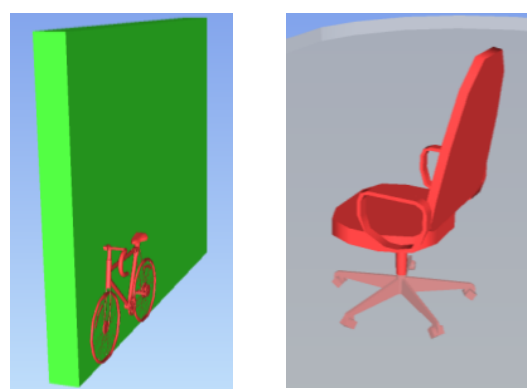

c)

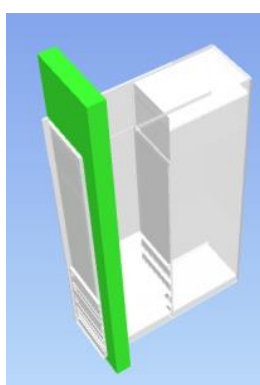

Figura 9: c) Colisão entre elementos de mobiliário não fixo e outros elementos; d) Colisões por interseções de tubagens com paredes divisórias.

Perante os resultados obtidos, houve a necessidade de reformular a estratégia de análise do modelo federado e prepará-lo para executar uma verificação mais fidedigna. Este processo que se seguiu foi moroso, visto que para filtrar a informação relevante foi necessário criar regras de verificação. As regras criadas consistiram em agrupar elementos do mesmo tipo dentro dos modelos, como por exemplo, criar um grupo só com os elementos estruturais do modelo de ARQ, outro grupo com o mobiliário não fixo, outro com os espaços arquitetónicos e transmitir ao programa para ignorar as colisões desses grupos com os restantes elementos.

Este procedimento permitiu filtrar a informação relevante. Tomando como exemplo o grupo 1, que analisava as colisões entre o modelo de arquitetura e o modelo de estruturas, após a criação de regras de análise, foram resolvidas 27886 colisões, restando apenas 18 colisões ativas por avaliar.

Este processo permitiu otimizar as listas de colisões e filtrar apenas as interferências que exigiam intervenção das equipas de projetistas. Para uma análise mais estruturada das colisões, estas foram agrupadas por piso. Nas figuras 10, 11 e 12 apresentam-se algumas das interferências relevantes e que foram posteriormente resolvidas no projeto. 


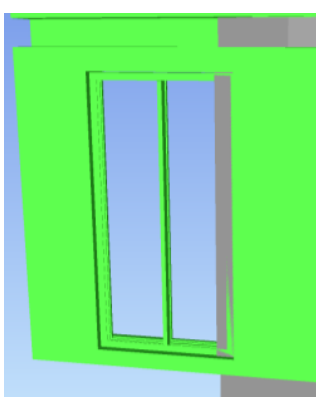

a)

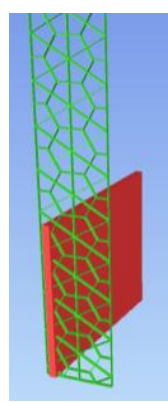

b)

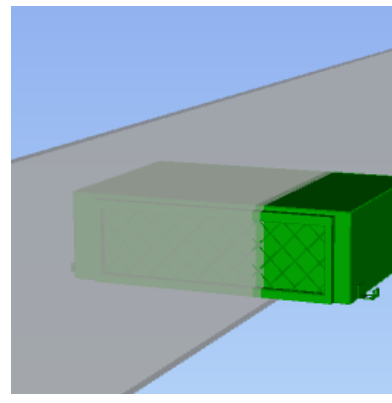

c)

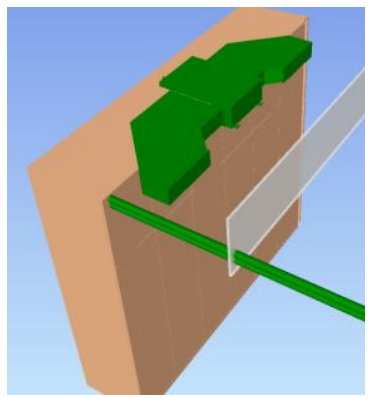

d)

Figura 10: a) Colisão entre pilar e porta; b) Colisão entre parede e painel de fachada; c) Colisão entre conduta de AVAC e parede divisória; d) Colisão entre mobiliário fixo e conduta de AVAC.

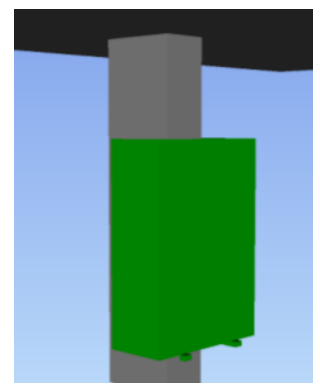

e)

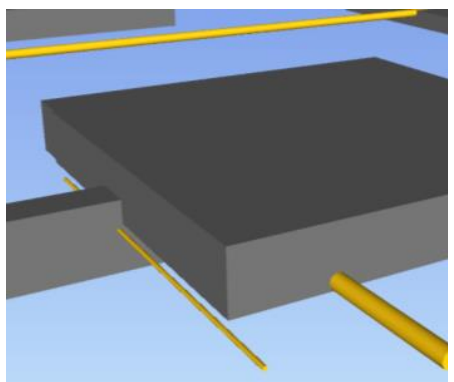

f)

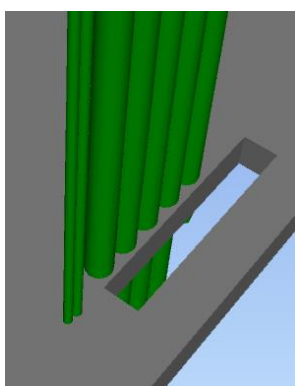

g)

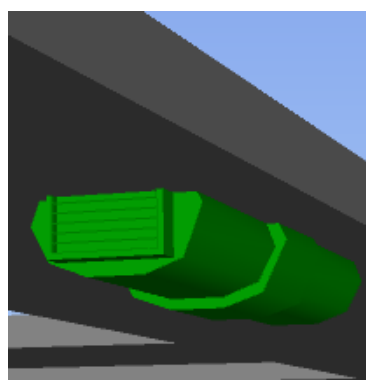

h)

Figura 11: e) Colisão entre equipamento de AVAC e pilar; f) Colisão entre capitéis e tubagens de gás; g) Colisão entre tubagens de AVAC e laje; h) Colisão entre conduta de AVAC e laje.

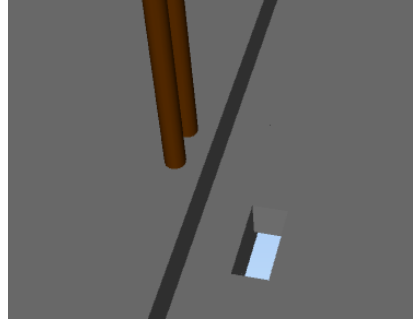

i)

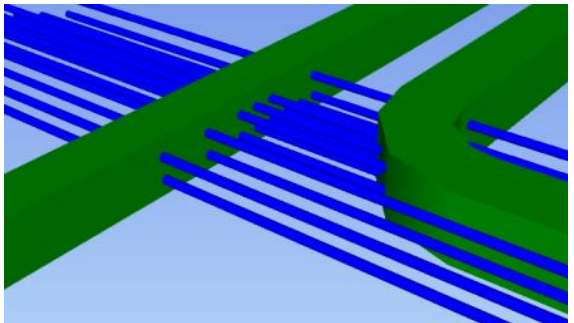

j)

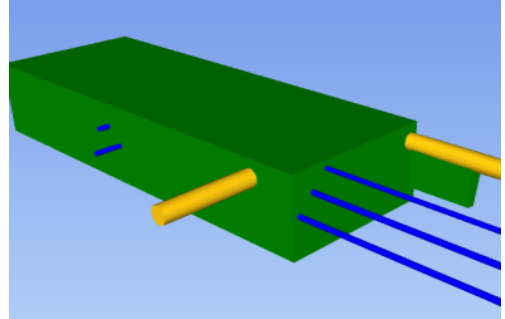

1)

Figura 12: i) Colisão entre tubagem de esgoto e laje; j) Colisão entre tubagens de água e condutas de AVAC; 1) Colisão entre tubagens de água e gás com conduta de AVAC.

A Coordenação 3D implica que se tenham novos cuidados durante a fase da modelação, que não eram tidos em conta quando a intenção de usar BIM no projeto era apenas a extração das peças desenhadas e das quantidades. A partir do momento em que se pretende fazer coordenação de modelos, deverá haver uma preocupação mais refinada, de modo a minimizar o número de colisões. É o caso da modelação das infraestruturas, onde não basta ter a preocupação com as interferências ao nível do plano, mas também a nível altimétrico. A maioria das colisões detetadas corresponde a interseções das condutas de AVAC com tubagens de águas ou gás. Muitas dessas colisões podem ser evitadas se, durante a fase da modelação, se tiver a preocupação de considerar diferentes planos altimétricos para cada disciplina. Os atravessamentos verticais também terão de ser bem compatibilizados, pelo que é importante 
que o modelo de estruturas defina corretamente os locais das aberturas das lajes para a passagem dos principais sistemas de tubagens. Um correto refinamento da modelação levará a uma otimização do processo de coordenação.

\subsection{Comunicação das colisões com recurso ao BIMcollab}

Tendo em conta a dimensão do modelo federado e por ser constituído por várias disciplinas, tornou-se necessário criar estratégias para o tratamento da informação extraída da análise de colisões. Foi crucial gerar grupos de análise de colisões entre disciplinas, para conseguir comunicar de forma eficaz as interferências relevantes do projeto às equipas responsáveis.

A comunicação das interferências começou por ser feita com recurso ao Navisworks, como estava inicialmente previsto no PEB. Após o BIM Manager realizar a análise, agrupou as colisões e atribuiu-as aos intervenientes, extraiu os relatórios de colisões em formato pdf e transmitiu-os aos responsáveis de cada disciplina.

Este procedimento revelou-se pouco prático no sentido em que se tornou difícil de identificar a posição dos elementos com colisões dentro dos modelos no Revit. Para contornar esta questão e facilitar a comunicação, optou-se por recorrer a uma outra ferramenta BIM, neste caso o BIMcollab, que utiliza o BCF como formato de colaboração. A informação em BCF é carregada para uma nuvem do BIMcollab, que comunica instantaneamente com o Revit e o Navisworks. Desta forma conseguiu-se atribuir equipas responsáveis para resolverem as colisões, que através do BIMcollab BCF Manager no Revit, conseguiam abrir diretamente as vistas no modelo e identificar facilmente as posições das interferências.

Na Figura 13 é apresentado um screenshot da lista de colisões identificadas no Navisworks (janela da esquerda) e a atribuição de uma das colisões à equipa responsável através do BIMcollab (janela da direita).

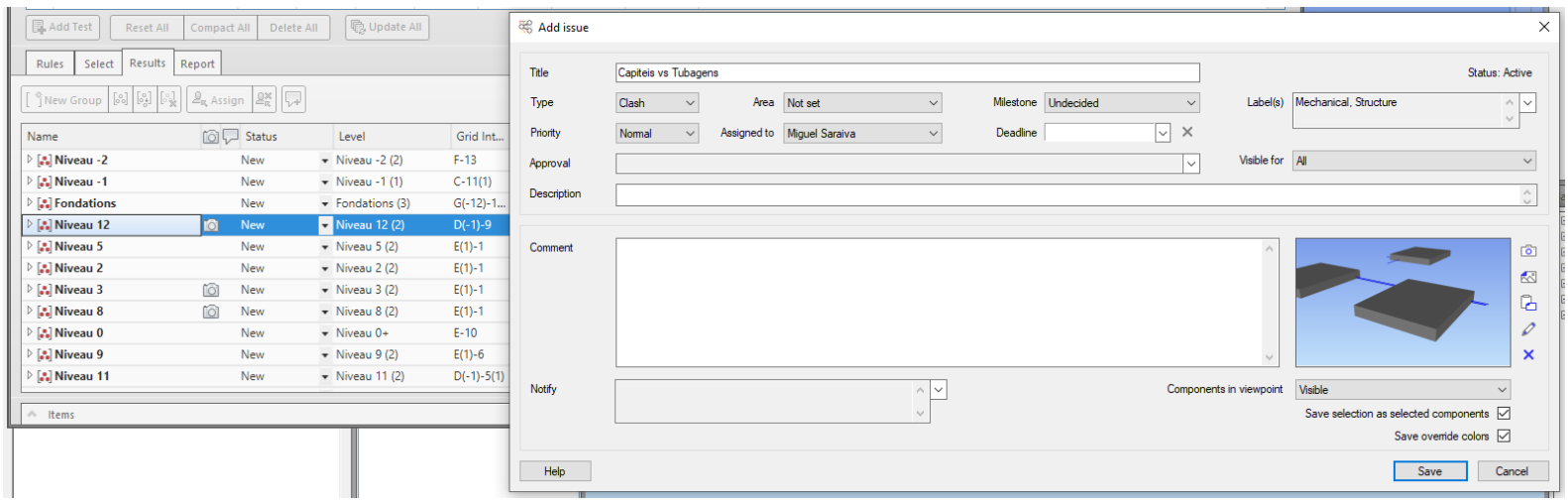

Figura 13: Atribuição de colisões pelo BIMcollab no Navisworks.

A forma de comunicar as colisões por BCF revelou-se muito intuitiva para os intervenientes. À medida que os conflitos iam sendo resolvidos, por parte das equipas de projeto, os responsáveis fechavam a notificação das colisões, alterando o estado da colisão para "resolvido" no BIMcollab BCF Manager. Caso fosse necessário, poderia ser deixado um comentário acerca da colisão. No ciclo de revisão seguinte, as colisões resolvidas seriam alvo de análise do BIM Manager, que teria a função de "fechar" ou "reativar" a interferência.

Na Figura 14 representa-se a identificação da colisão dos elementos no modelo em Revit (janela da esquerda) e a síntese da informação da colisão do BIMcollab (janela da direita). 


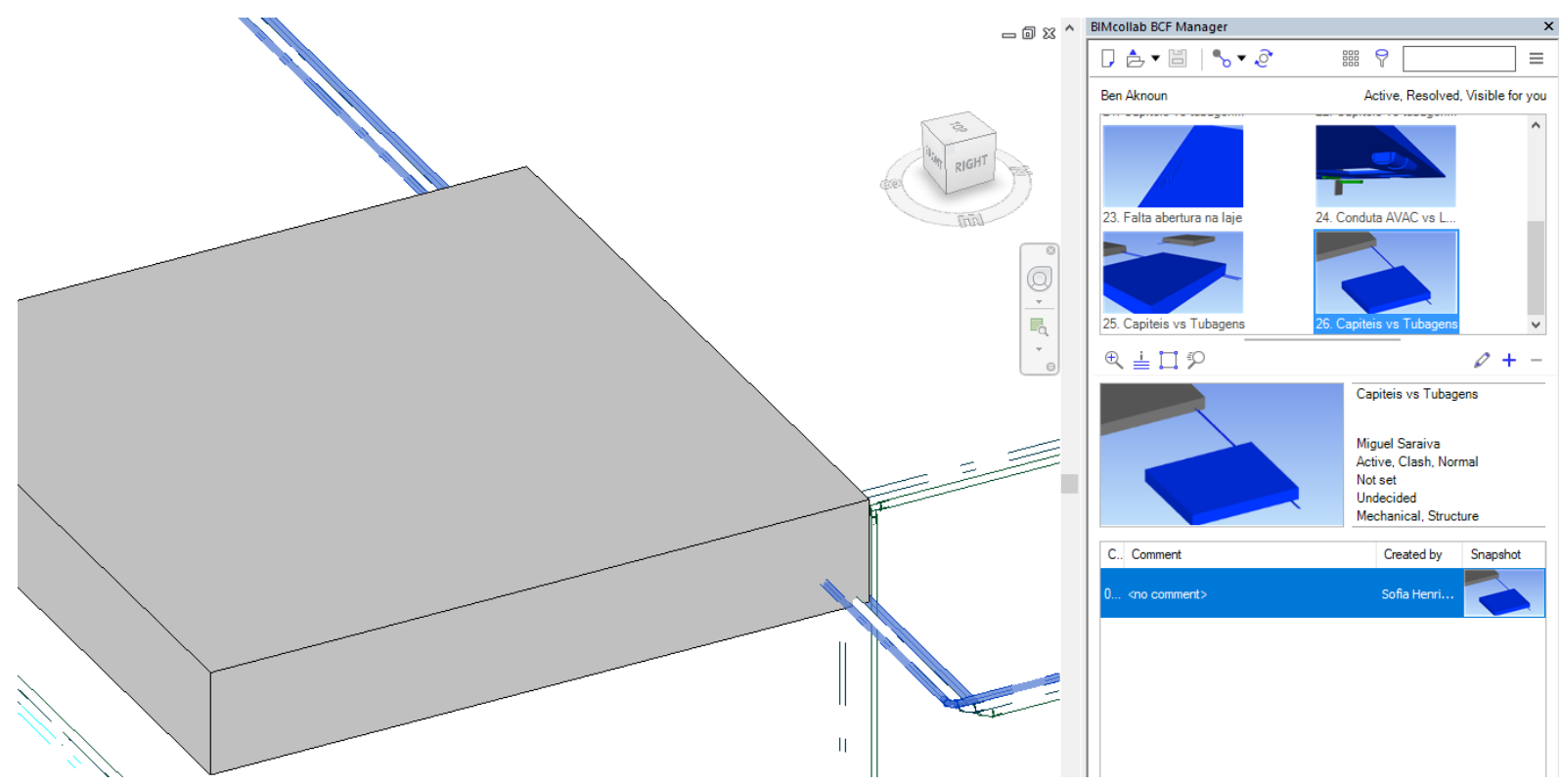

Figura 14: Identificação das colisões pelo BIMcollab no Revit.

\section{Considerações finais}

A experiência obtida com a apresentação do projeto de arquitetura ao cliente, com recurso a ferramentas BIM, permitiu concluir que este uso BIM é extremamente útil porque permite ajudar o cliente a compreender melhor o projeto e assim reduzir o risco de alterações futuras. Para tirar mais proveito deste uso BIM, em projetos futuros poderá auxiliar-se o cliente a desenvolver as suas competências BIM e que, por intermédio de plataformas de visualização de modelos BIM, poderá realizar ao longo do desenvolvimento do projeto, revisões mais detalhadas dos modelos das várias disciplinas, inclusive comunicar diretamente por intermédio dessas plataformas.

O uso de ferramentas BIM para a coordenação do projeto revelou-se muito eficiente na deteção das colisões e na sua comunicação. Grande parte das interferências conseguiram ser facilmente detetadas e resolvidas durante o projeto de execução. Porém a coordenação 3D envolve um volume de trabalho significativo e exige bastante tempo de análise. Neste projeto em específico, o BIM Manager acumulou as funções de apoio ao desenvolvimento dos modelos BIM com a coordenação 3D. Em projetos futuros, as funções do BIM Manager devem focar-se na gestão e verificação dos modelos de acordo com o estipulado no PEB e na gestão da plataforma colaborativa, nomeando um BIM Coordinator, que fica responsável pela coordenação 3D.

\section{Referências}

[1] Computer Integrated Construction Research Program. (2011). "BIM Project Execution Planning Guide - Version 2.1.” May, The Pennsylvania State University, University Park, PA, USA; 